\title{
Literatura e formação moral em Jane Austen e em David Hume
}

\author{
Marcos Ribeiro Balieiro
}

UFS 

Jane Austen é, sem dúvida, uma autora cujo trabalho goza de popularidade bastante duradoura. Isso fica evidente quando atentamos para o grande número de adaptações que suas obras vêm recebendo para o cinema ou para a televisão. Orgulho e Preconceito, por exemplo, rendeu no mínimo dois filmes e duas séries de televisão. Razão e Sensibilidade, por sua vez, já foi adaptada na forma de filme e, por duas vezes, na de série televisiva. Temos, também, uma adaptação cinematográfica de Emma, além de homenagens literárias que incluem títulos satíricos como Orgulho e Preconceito e Zumbis e Razão e Sensibilidade e Monstros Marinhos.

Ainda que parte do interesse dos romances de Austen se deva ao teor romântico de seus livros, o qual tem papel considerável no que diz respeito a atrair o grande público, isso não bastaria para explicar o interesse da crítica literária especializada nos livros dessa autora e, mais ainda, o interesse recente de historiadores da filosofia em sua obra. Evidentemente, não pretendemos, aqui, dar conta dos vários motivos pelos quais Austen é considerada uma escritora de primeira grandeza, ou daqueles pelos quais se considera que seus escritos tenham algo como um teor verdadeiramente filosófico. Uma tarefa como essa exigiria mais tempo, mais espaço e mais erudição do que podemos dizer que possuímos. Limitar-nos-emos, então, a realizar, de maneira que talvez se revele demasiadamente breve, uma comparação entre o modo como Austen concebe a literatura enquanto ferramenta de formação moral com o tratamento desse tema oferecido por David Hume, pensador por cuja obra ela admitiu, em carta, nutrir admiração. Devemos observar que comparações entre Austen e Hume não são uma completa novidade; alguns estudiosos já tentaram estabelecer relações desse tipo, a exemplo do esforço que E. M. Dadlez realizou em seu Mirrors to One Another: Emotion and Value in Jane Austen and David Hume. De qualquer modo, o tema que propomos aqui pode ser relevante porque permite que sejam estabelecidas formas relativamente originais de conceber os modos como Austen e Hume viam a relação que deve haver entre aquele 
que escreve uma obra e o leitor desta e, no caso de Hume, especificamente, talvez possamos encontrar, em alguma medida, pistas importantes para os propósitos que esse autor considerava que a própria filosofia deveria ter.

Seria impraticável, em um trabalho como este, procurarmos dar conta da totalidade tanto dos textos de Austen quanto dos de Hume. Faz-se necessário, então, que optemos por um recorte que nos permita, a partir de um volume de textos que se mostre mais viável, extrair consequências gerais efetivamente válidas para os autores de que trataremos. Nesse sentido, as obras de Austen que privilegiaremos aqui serão A Abadia de Northanger e Orgulho e Preconceito. A primeira foi escolhida por conter considerações bastante diretas acerca da relação entre literatura e formação moral e a segunda porque, além de ser o livro mais célebre de Austen (e, portanto, o mais palatável para um eventual leitor que não tenha um contato aprofundado com sua obra), apresenta personagens com caracteres bem definidos o suficiente para garantir que nossa exposição seja tão clara quanto possível. No que diz respeito a Hume, lidaremos principalmente com os Ensaios Morais, Políticos e Literários, entre os quais podemos encontrar um número considerável de textos em que o autor discorre sobre o tema de que nos ocuparemos. Ainda assim, sempre que for necessário, trataremos de recorrer a outros romances de Austen, ou a outras obras de Hume.

Passemos, então, à nossa análise do modo como o tema da relação entre literatura e formação moral é desenvolvido por esses dois autores. Parece-nos, antes de qualquer outra coisa, que eles têm em comum o fato de considerarem que a dedicação excessiva aos estudos e à leitura, em detrimento do cultivo das boas relações sociais, é extremamente perniciosa. Essa é uma afirmação que Hume faz de maneira bastante explícita em "Da Escrita de Ensaios". Nesse texto, logo após afirmar que o mundo da conversação teria muito a perder quando separado de algum conhecimento de temas como história, poesia, política e filosofia, o autor nos informa que 
Por outro lado, o aprendizado sofreu perdas igualmente grandes ao ser trancado em colégios e em celas, e separado do mundo e da boa companhia. Por esses meios, tudo aquilo a que chamamos belles lettres se tornou totalmente bárbaro, sendo cultivado por homens sem qualquer gosto pela vida ou maneiras, e sem aquela liberdade e aquela facilidade de pensamento e de expressão que só podem ser adquiridas pela conversação (Hume, 1985, p. 534).

A mensagem é inequivocamente clara: a separação entre o mundo erudito e o da conversação teria, consequências que, além de bastante desagradáveis, poderiam ocasionar uma verdadeira derrocada de qualquer coisa parecida com uma literatura minimamente aceitável. Além disso, Hume nos informa que "Até mesmo a filosofia se reduziu a destroços por esse modo lamentoso e recluso de estudo, e se tornou tão quimérica em suas conclusões quanto ininteligível em seu estilo e em sua maneira de exposição" (Ibid., p. 534-5). Parece não haver dúvida, portanto, de que Hume, em alguma medida, considerava impossível que a filosofia, bem como a literatura de maneira geral, pudesse se servir de algo como uma forma de dedicação aos estudos que é, no ensaio a que acabamos nos referir, tratada de maneira bastante impiedosa. Vale lembrar que esse não é o único momento da obra de Hume em que vemos a participação na vida social ser apresentada como algo que pode colaborar para as atividades do filósofo. Ao fim do Livro III do seu Tratado da Natureza Humana, o autor já afirmava que se pode fazer filosofia como um anatomista ou como um pintor. Este buscaria, por meio de raciocínios mais simples e de imagens vívidas, incitar o leitor à prática da virtude. $\mathrm{O}$ anatomista, por sua vez, teria por objetivo realizar uma análise bastante detalhada da natureza humana. No Tratado, Hume tratou de afirmar que considerava altamente improvável conciliar esses dois caracteres (Id., 2000). Como se sabe, o autor mostrou uma posição bastante diferente quanto a isso em textos posteriores. Isso fica evidente 
quando, na Seção I da Investigação sobre o Entendimento Humano, ele acena com a proposta de conciliar o anatomista e o pintor (Id., 1999). Não é apenas nos Ensaios, portanto, que Hume se propõe a escrever para um público que iria além do mundo eruditoº

O que nos interessa aqui, porém, é menos o efeito que a cisão entre o mundo erudito e o da conversação teria tido sobre a filosofia do que os efeitos nefastos que esse fato pode acarretar para $a$ própria vida daqueles que se entregam ao isolamento e ao estudo excessivo. Esse é um ponto que Hume parece estabelecer em diversos momentos de sua obra. A Conclusão do Livro I do Tratado, por exemplo, mostra um autor que, por conta de seu ceticismo excessivo, chega a perceber-se como "um monstro estranho e rude, que, não sendo capaz de se misturar e de se unir à sociedade, foi expelido de todo o comércio humano, e completamente abandonado e desconsolado" (Hume, 2000, p. 172). É verdade que, nesse caso, o problema parece ser mais o ceticismo atingido após as reflexões penosas do restante do Livro I, mas temos outras evidências de que não é apenas esse o caso. Não podemos nos furtar a observar que, ainda na Conclusão do Livro I, Hume afirma que os erros em filosofia são apenas ridículos, enquanto aqueles que dizem respeito à religião são perigosos, mas ainda assim a filosofia é apresentada como um possível guia para a vida (Id., 2000). Devemos lembrar, ainda, o exemplo de Diógenes, que tem papéis diferentes no Tratado e na Investigação sobre os Princípios da Moral. Em sua primeira obra, o autor apresenta Diógenes como uma exceção, um caso que não invalida o fato de que os erros em

\footnotetext{
1 Isso é importante porque, de outro modo, poder-se-ia argumentar que Hume, consciente das características que o ensaio tem enquanto forma literária, teria direcionado seus próprios Ensaios Morais, Políticos e Literários a um público mais amplo, mas que isso não é algo que poderia ser dito de outras obras. Não é o caso. Sabemos que a reformulação do Tratado na forma das duas Investigações e da Dissertação sobre as Paixões teve por um de seus objetivos tornar suas teorias mais acessíveis para o, digamos, leitor comum. A seriedade dessa empreitada fica, por vezes, evidente em observações que o autor faz ao longo dos textos. Um bom exemplo talvez seja o parágrafo final da Parte I da Seção V da Investigação sobre o Entendimento Humano.
} 
filosofia são apenas ridículos. Na segunda Investigação, porém, o filósofo antigo é apresentado como um exemplo dos perigos de se viver de acordo com princípios preferidos e tentar fazer com que o mundo percebido se adeque a ele (Id., 1998). Parece, então, que Hume passou cada vez mais a ver a filosofia como algo que poderia ter efeitos bastante concretos sobre as vidas daqueles que se dedicam a ela e, nesse registro, as consequências podem ser bastante danosas quando a vida comum é posta de lado em favor de uma devoção excessiva a princípios especulativos².

A ideia de que o abandono da sociabilidade em favor dos livros pode ser perniciosa está presente, também, na obra de Jane Austen. A Abadia de Northanger, primeiro romance escrito por ela, traz exemplos bastante claros disso. Catherine Morland, a protagonista, toma uma série de decisões que lhe são prejudiciais justamente por ser uma leitora inveterada de gothic novels. Essas decisões, ao longo da narrativa, trazem para ela todo tipo de consequências indesejáveis, que incluem desde más escolhas no que diz respeito a suas amizades até a crença, sem qualquer bom motivo, de que o General Tilney, pai do herói da história (por quem, evidentemente, a protagonista está apaixonada), teria assassinado sua esposa (Austen, 2007). Temos um exemplo igualmente crista-

2 Faz sentido, então, que boa parte dos comentadores que se dedicaram a estudar os quatro ensaios de Hume que têm nomes de escolas filosóficas vejam, por parte do filósofo, uma censura a um tipo que recebe o nome de "O Platônico", e que é não um verdadeiro defensor das doutrinas platônicas, mas um "homem de contemplação e devoção filosóficas" (Hume, 1985, p. 155 (grifo nosso)). Hume, é verdade, não faz censuras explícitas ao "platônico", mas o consenso entre os comentadores é que, ainda que este seja, em alguma medida, uma alegoria de fatores que são indissociáveis da prática filosófica (tais como, por exemplo, a dedicação que ela exige), apresenta, inclusive por conta de seu isolamento do mundo, aspectos que Hume consideraria inaceitáveis. Alguns comentadores, como John Waldimir Price (1965) e Donald Livingston (1988), nem mesmo vêem no platônico descrito no ensaio quaisquer elementos dignos de elogio. Price recorre a uma análise estilística para tentar mostrar que Hume, ao atribuir ao platônico um tom excessivamente pomposo e declamatório, busca justamente mostrar que até o tom empregado por ele está fadado a ser inaceitável. Livinstgon, por sua vez, defende que Hume não pode aceitar aquilo que é proposto por "seu" platônico justamente porque este tenderia a ignorar completamente fatores da vida comum que, no fim das contas, poderiam fazer com que ele filosofasse de maneira mais consistente. 
lino em Orgulho e Preconceito: Mary, irmã da protagonista Elizabeth, é apresentada não apenas como alguém que, por conta de sua dedicação aos livros, deixa de lado a convivência mesmo com as pessoas mais próximas. Austen trata de deixar claro que Mary, ao menos em parte por não dar a devida atenção à sociabilidade, é alguém que pode ser capaz de recitar preceitos morais com grande desenvoltura, mas não tem um julgamento exatamente apurado no que diz respeito às questões da vida comum. Apesar de sua técnica ser superior à de Elizabeth no que diz respeito ao canto e ao piano, sua apresentação carece de espírito, o que faz com que ela falhe em agradar sua audiência e, talvez ainda mais grave, sem que ela se dê conta disso. Diferentemente de todas as suas irmãs (e de todas as outras personagens), ela considera que não seria de todo ruim ter a oportunidade de se casar com o Sr. Collins, homem bastante desagradável por conta de sua pompa excessiva e de sua atitude demasiadamente servil para com a sua benfeitora. Ao fim da história, descobrimos que

Mary foi a única filha que ficou em casa, e ela era necessariamente distraída de sua busca de realizações pelo fato de a Sra. Bennet ser completamente incapaz de ficar sozinha. Mary foi obrigada a se misturar mais com o mundo, mas ainda podia moralizar sobre qualquer visitante matinal, e já que não era mais mortificada por comparações entre a beleza de suas irmãs e a sua própria, seu pai suspeitava que ela havia se submetido a essa mudança sem muita relutância (Id., 1994, p. 297).

É importante observarmos que, por "realizações", deve-se entender, aí, progresso nos estudos. Pode ser oportuno, também, notar que comparações desfavoráveis entre a beleza de Mary e a de suas irmãs eram ao menos parte do que a incomodava, em momentos anteriores da história, quando ela precisava se "misturar com o mundo". Finalmente, não podemos nos furtar de lembrar que a companhia da Sra. Bennet estava longe de ser agradável. O fato de esta senhora ser completamente incapaz de apresen- 
tar um comportamento polido, socialmente aceitável, é bastante enfatizado por Austen, e chega a ter consequências importantes, por tornar menos aceitável o relacionamento de suas duas filhas mais velhas com os cavalheiros que, ao final da história, casar-se-ão com elas de qualquer maneira. A Sra. Bennet, de fato, é uma companhia tão pouco agradável que mesmo o Sr. Bingley, apresentado por Austen como um exemplo de amabilidade, cansa-se dela após um período de convivência mais prolongada. Podemos concluir, então, que Mary, ainda que não possa ser considerada uma personagem má, tem um desfecho insatisfatório para ela, "presa” em casa com uma companhia bastante desagradável. Seu destino só não é pior do que o de sua irmã Lydia, que, sendo um verdadeiro modelo de insensatez, termina a história em um casamento bastante desvantajoso, com um homem que, além de não amá-la, tem uma quantidade excepcionalmente grande de vícios (Id., 1994).

Mary não é a única personagem de Orgulho e Preconceito que tem um caráter imperfeito por conta de seu isolamento. O Sr. Bennet, pai da protagonista e de suas irmãs (e também de Mary, portanto), não parece ter grande apreciação pela vida social; prefere passar a maior parte do tempo sozinho em sua biblioteca. É descrito como um pai razoavelmente afável, mas também como alguém cujo principal deleite é zombar, ainda que de maneira amigável, daqueles que o cercam. Sua conduta, ainda que de maneira geral correta, não está isenta de eventuais inconvenientes. $\mathrm{O}$ fato de ele ser um "verdadeiro filósofo" (Ibid., p. 183) pode fazer com que suporte com serenidade um casamento sem amor, mas não lhe confere a habilidade de administrar bem suas finanças, nem a de evitar que uma de suas filhas seja seduzida por um homem indigno. A "filosofia" a que se dedica o Sr. Bennet, então, não é de todo má, na medida em que colabora para que ele suporte com serenidade as adversidades que lhe são impostas (e isso também poderia ser dito de Mary), mas o isolamento a que ele se submete, no fim das contas, parece inegavelmente prejudicial. 
Parece, então, não haver dúvidas de que tanto Austen quanto Hume considerariam que filosofia e literatura devem, para trazer bons resultados, estar incorporadas à vida comum, a qual tem mesmo certa precedência. É preciso verificar, então, os modos como se daria essa incorporação. Uma pista valiosa pode ser encontrada no Capítulo V de A Abadia de Northanger, no qual vemos uma defesa bastante ferrenha da novela por parte de Austen, seguida, justamente, por uma crítica àquele que teria sido um dos grandes modelos em que Hume teria se inspirado para compor seus Ensaios. Depois de mostrar as críticas que uma jovem poderia sofrer por conta do hábito de ler novelas, a autora faz a seguinte afirmação:

Agora, se a mesma senhorita estivesse envolvida com um volume de The Spectator, ao invés de uma tal obra, quão orgulhosamente ela mostraria o livro, e diria seu nome, ainda que houvesse uma grande possibilidade de ela não se interessar por qualquer parte dessa volumosa publicação, da qual tanto o conteúdo quanto o estilo não desagradariam um jovem de bom gosto, já que a substância de suas folhas consiste tão frequentemente em afirmações de circunstâncias improváveis, caracteres não naturais e tópicos de conversação que não mais dizem respeito a ninguém que ainda esteja vivo, e sua linguagem, também, é grosseira a ponto de dar uma ideia não muito favorável da época que podia suportá-la (Id., 2007, p. 1092).

Não é demais enfatizar que The Spectator é descrito por Austen como uma publicação que traz "circunstâncias improváveis, caracteres não naturais e tópicos de conversação que não mais dizem respeito a ninguém que ainda esteja vivo”. É oportuno, também, lembrar que John Thorpe, personagem extremamente desagradável que mostra algum interesse pela protagonista Catherine Morland, é um dos tais críticos de novelas contra os quais Austen se insurge. Parece, então, que temos, aí, um ponto de discordância entre a autora e Hume, especialmente se lembrarmos que ele, em textos como "Da Escrita de Ensaios" e "Do Estudo 
da História", reprova o fato de as mulheres terem uma preferência notável não apenas por livros religiosos, mas também por novelas que trazem histórias de amor (Hume, 1985). A aparência de discordância torna-se ainda mais notável quando nos lembramos de que o propósito declarado de The Spectator, que exerceu uma influência bastante clara sobre os Ensaios de Hume, era trazer a filosofia para os cafés e para o ambiente familiar, procurando, então, atingir um público mais amplo do que aquele que, algum tempo mais tarde, o filósofo escocês denominaria o mundo erudito. Parece, ainda, particularmente grave que Austen não critique apenas The Spectator, mas a época que podia suportá-lo. A acusação é grave porque, para ela, essa publicação, que provavelmente era vista à época como apropriada para a educação e o entretenimento de senhoritas, teria, por conta das circunstâncias, dos tópicos e dos caracteres que apresentava, efeitos deletérios para a formação de seus jovens leitores.

Por outro lado, Austen apresenta, ainda em A Abadia de Northanger, um elogio da História da Inglaterra de Hume, por meio de Eleanor Tilney, irmã do herói da trama e uma jovem que é apresentada como bastante amável e sensata. Esse parece um elogio bastante significativo, já que o filósofo escocês, depois de recomendar a leitura de textos históricos às mulheres, afirma que o estudo dessa disciplina acarreta três vantagens: ela "diverte a imaginação, melhora o entendimento e fortalece a virtude" (Ibid., p. 565). Mais do que isso, Hume considera que os historiadores sempre teriam sido "os verdadeiros amigos da virtude" (Ibid. p. 567). A vantagem deles sobre os filósofos seria justamente o fato de não se prenderem a uma visão demasiadamente abstrata que pode fazer com que os sentimentos apropriados acerca de assuntos morais diversos sejam incapazes de agir. O historiador, diz Hume, coloca seu leitor diante de casos concretos, mas em que interesses particulares deste último não estão envolvidos, permitindo, desse modo, que o leitor, ao mesmo tempo em que aumenta a gama de experiências com que poderá contar, seja colocado em uma 
posição privilegiada para fazer julgamentos morais, já que seus sentimentos acerca de temas morais serão tocados sem a interferência do interesse próprio.

Não devemos pensar, entretanto, que é apenas no que diz respeito à história que Hume seria, por assim dizer, merecedor dos elogios de Austen. Retornemos, agora, às considerações que ela empreende em A Abadia de Northanger. Ainda que o Capítulo $\mathrm{V}$ contenha uma defesa das novelas de que não é necessário duvidar, não podemos perder de vista que o livro como um todo pode ser considerado justamente um alerta contra os perigos de se pensar que as coisas transcorrerão na vida real do mesmo modo como se desenrolam nos livros. Catherine Morland, como já vimos, sofre uma série de infortúnios justamente por cometer esse engano. Suas leituras assíduas de gothic novels a tornam dona de uma imaginação excessivamente fértil, e também, como não poderia deixar de ser, uma garota um tanto insensata. Nesse sentido, se ela pode ter um final mais desejável que o de Mary, é por aprender a duras penas que a vida não segue os mesmos padrões que o enredo de seus livros preferidos. É verdade, evidentemente, que as obras que recebem a atenção de Catherine são bastante diferentes daquelas com que Mary ocupa seu tempo, mas parece que, na obra de Austen, a dedicação excessiva a qualquer tipo de leitura parece ter efeitos indesejáveis³. Mary pode se dedicar a livros que seriam considerados mais nobres, mas isso não a torna mais sensata, nem uma companhia mais agradável. Nesse sentido, parece mesmo que Catherine está em situação mais vantajosa: é mais sociável que Mary e, de certa forma, é sua abertura para a convivência e para o "mundo real" que termina por levá-la a um desfecho plenamente feliz. Parece, então, que, se Austen sente a

3 Talvez seja oportuno observar, ainda, que a ideia de que a felicidade pode ser alcançada quando abandonamos, em favor da vida comum, princípios que antes defendíamos obstinadamente é importante na obra de Austen. Um bom exemplo desse fato pode ser encontrado no desfecho conferido a Maryanne Dashwood ao fim de Razão e Sensibilidade. 
necessidade de defender novelas contra os defensores esnobes de The Spectator, isso não se deve ao fato de ela estar satisfeita com as novelas de sua época, ou por considerar que elas bastariam para formar o caráter de uma senhorita. O que ela pretende é um ataque a uma publicação que, talvez mais do que qualquer novela, seria danosa justamente por ter o objetivo de promover princípios demasiadamente afastados da "vida real", ainda que expostos em uma forma que se pretendia palatável para o homem comum.

Isso não quer dizer, é claro, que as gothic novels ou os romances açucarados fossem endossados por Austen. São bastante visíveis, ao longo de sua obra, comentários bastante aguçados de costumes de sua época. Nesse sentido, parece que a autora buscava oferecer um tipo de literatura que se prestasse não apenas a entreter, mas também, em certa medida, a instruir seus leitores e a formar neles uma visão mais realista da sociedade em que estavam inseridos. Isso só seria possível se a literatura apresentasse modelos que estivessem de acordo com aquilo que era efetivamente observável no mundo. Com isso, a leitura poderia contribuir em alguma medida para formar pessoas mais sociáveis.

Essa é uma formulação que certamente não desagradaria Hume. Em "Da Delicadeza de Gosto e da Delicadeza de Paixão", ele observa que o cultivo do gosto por meio não apenas da leitura de bons livros, mas da contemplação de boas obras de arte e da audição de boa música, pode contribuir para a formação do caráter na medida em que contribui para abater as paixões violentas e para fortalecer nosso juízo no que diz respeito a questões morais, além de favorecer o desenvolvimento das boas amizades (Hume, 1985). Além disso, ensaios que já mencionamos neste texto, como "Da Escrita de Ensaios" e "Do Estudo da História", deixam claro que o filósofo pretendia que alguma dedicação a temas de história, política, poesia ou filosofia poderiam contribuir para formar pessoas mais sensatas e mais agradáveis. Essa é uma preocupação que se tornou bastante proeminente nas obras de Hume posteriores ao Tratado da Natureza Humana. Isso fica 
evidente não apenas nos Ensaios ou na História da Inglaterra. É notável, por exemplo, o recurso a exemplos históricos e cotidianos na Investigação sobre os Princípios da Moral. Ainda que devamos admitir que esse procedimento ecoa a Introdução do Tratado, na qual o autor afirmava que, na impossibilidade de se realizar experimentos controlados com a humanidade, devemos recorrer à observação da vida humana tal como ela se nos apresenta, não podemos negar, também, que o fato de Hume conceder um peso tão grande aos exemplos em sua argumentação faz com que ela seja mais acessível ao leitor comum. Desse modo, podemos ver no filósofo escocês um autor que escolheu cada vez mais apresentar aos seus leitores casos concretos a partir dos quais extrairia suas conclusões, evitando, quando possível, argumentos excessivamente longos e intrincados. Esse foi, sem dúvida, um esforço importante no sentido de conciliar os caracteres do pintor e do anatomista.

Não estamos certos de quais entre os textos que compõem a obra de Hume teriam sido considerados meritórios por Jane Austen. Talvez os Ensaios, inspirados, como sabemos, por The Spectator, não gozassem todos de favor incontestável por parte dessa autora. Talvez, ainda, textos como a Investigação sobre os Princípios da Moral ou a História Natural da Religião, por mais que contenham uma quantidade enorme de casos concretos, fossem considerados por ela, ao menos em algumas passagens, como abstratos demais. Não se pode negar, entretanto, que tanto Hume quanto Austen consideravam que só seria possível que a literatura (em qualquer uma de suas formas) fosse de alguma valia para a formação moral quando, além de não pretender isolar aqueles que se dedicam a ela do convívio social, se dispusesse a não perder de vista o mundo que, ao fim e ao cabo, os filósofos mais abstratos inevitavelmente compartilham com o homem comum. 


\section{Bibliografia}

AUSTEN, J. The Complete Novels of Jane Austen. Londres, Wordsworth, 2007.

AUSTEN, J. Pride and Prejudice. Londres, Peguin Books, 1994.

DADLEZ, E. M. Mirrors to one another: emotion and value in Jane Austen and David Hume. Nova York, Wiley-Blackwell, 2009.

HUME, D. An Enquiry concerning Human Understanding. Oxford; Nova York, Oxford University Press, 1999.

An Enquiry concerning the Principles of Morals. Oxford; Nova York, Oxford University Press, 1998.

Fund, 1985 .

A Treatise of Human Nature. Oxford, Nova York, Oxford University Press, 2000.

LIVINGSTON, Donald. Philosophical melancholy and delirium: Hume's pathology of philosophy. Chicago, The University of Chicago Press, 1998.

PRICE, J. V. The Ironic Hume. Austin, University of Texas Press, 1965. 
